\title{
INTERCEPTAÇÃo TELEFôNICA E LINGUAGEM
}

\author{
Daniel Fabio Fantini \\ Departamento de Polícia Federal - Brasil

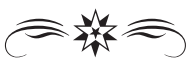

\section{RESUMO}

O presente trabalho discorre sobre os aspectos linguísticos inerentes ao conteúdo das interceptações telefônicas. Neste prisma, tendo em vista os estudos sobre a linguagem, aborda-se o assunto pela dimensão pragmática, considerando a sua aplicação empírica. Em que pese as dificuldades de sistematização de uma abordagem teórica sobre o uso da linguagem, as teorias dos atos de fala e dos atos de fala indiretos, elaboradas por John L. Austin e John Searle, respectivamente, oferecem soluções adequadas para explicar os fenômenos linguísticos relativos às conversas mantidas entre possíveis autores de crime, interceptadas no bojo da investigação criminal. As teorias mencionadas fornecem instrumental teórico aos investigadores para que possam interpretar, apropriadamente, quais os significados das palavras captadas nas conversas interceptadas conforme o seu uso. No caso, ao destacarem que o "dizer algo" é, ao mesmo tempo, "fazer algo", revelam que a linguagem captada pode ser melhor compreendida quando se analisam as forças ilocucionárias que regem os atos de fala da comunicação. Por fim, a teoria dos atos de fala indiretos fornece alguns elementos que possibilitam a compreensão de atos de fala que possuem mais de uma força ilocucionária, um explícito e outro implícito, facilitando o entendimento das conversas captadas, mesmo que estas se utilizem de expressões codificadas, gírias ou mensagens cifradas, como corriqueiramente são utilizadas pelos autores de crimes.

PALAVRAS-CHAVE: Interceptação telefônica. Investigação criminal. Linguagem. Pragmática. Jogo de Linguagem. Wittgenstein. Atos de fala. Austin. Searle.

\section{INTRODUÇÃo}

A interceptação das comunicações telefônicas com o fim de servir à investigação criminal tem assento na Constituição da República de 1988, especificamente no artigo $5^{\circ}$, inciso XII, tratando-se de medida excepcional a ser autorizada com base nas prescrições do próprio texto constitucional e da Lei n. ${ }^{0} 9.296$ de 24 de julho de 1996. 
Uma profusão de artigos já foi publicada sobre o tema, versando sempre sobre um único aspecto do assunto: os limites constitucionais e legais da medida investigativa no sistema jurídico pátrio. Evidentemente que o tema possui especial interesse para o Direito posto que envolve a mitigação de direitos fundamentais do homem, mormente a privacidade, intimidade e a liberdade.

Não obstante, ultrapassadas as discussões sobre os aspectos formais e legais que autorizam a implementação da medida excepcional da interceptação das comunicações telefônicas, percebe-se que existem poucos estudos que enfoquem como devem ser analisados os resultados obtidos por meio dessa técnica investigativa.

Ou seja, há muitos textos que tratam das hipóteses em que o uso da interceptação das comunicações telefônicas é autorizado, mas poucos estudam a linguagem contida nas conversas interceptadas e como elas devem ser interpretadas.

Este estudo deve servir de reflexão para todos os operadores do Direito, incluindo defensores, acusadores e o próprio julgador, quando lidam com os procedimentos que envolvem a interceptação das comunicações telefônicas, mesmo porque as provas colhidas, consistentes nas gravações das conversas, serão apreciadas e servirão de lastro para ações, argumentações e decisões. Contudo, entendo que os maiores interessados no assunto são os próprios investigadores, por excelência, aqueles que integram a Polícia Judiciária, instituição que possui respaldo legal para conduzir a diligência (art. 6. ${ }^{\circ}$, caput, da Lei ${ }^{\circ}$ 9.296/96) e apresentar os resultados obtidos.

Na falta de maiores reflexões sobre o agir policial é comum atribuirmos ao sucesso, obtido no improviso, o título de tirocínio policial. Já quando não se atinge o resultado esperado, não há meios de se apontar as razões do fracasso. Desta forma, o estudo pretende apontar minimamente, dentro de uma concepção pragmática, conceitos teóricos que justifiquem as interpretações e conclusões corriqueiramente feitas pelos investigadores quando realizam uma apuração utilizando a interceptação das comunicações telefônicas como uma das técnicas disponíveis. 


\section{A INTERCEPTAÇÃO DAS COMUNICAÇÕES TELEFÔNICAS}

A interceptação das comunicações telefônicas é medida extremamente eficaz no combate à criminalidade, uma vez que proporciona uma forma de conhecer, profundamente, os métodos utilizados na prática do crime, a participação efetiva de cada indivíduo nas condutas investigadas e a possibilidade de se prever e prevenir a prática de outros eventuais ilícitos. Além disso, é fonte inequívoca de prova perante o Poder Judiciário, quando executada dentro dos ditames do devido processo legal.

Juridicamente não há definição sobre o conceito de telefonia, embora o antigo Código Brasileiro de Telecomunicaçôes, Lei n. ${ }^{\circ} 4.117$ de 27 de agosto de 1962, estabelecesse no artigo $4^{\circ}$, que "telefonia é o processo de telecomunicação destinado à transmissão da palavra falada ou de sons". Contudo, a Lei n. ${ }^{\circ} 9.472$ de 16 de julho de 1997, revogou expressamente esse diploma legal, conforme dispôs o artigo 215, inciso I.

Não obstante, por ocasião da Lei n. ${ }^{\circ}$ 9.296/96, Grinover (1997) define o conceito jurídico de interceptação das comunicações telefônicas, atribuindo-o essencialmente à existência de uma terceira pessoa que escuta ou grava a conversa telefônica:

Por mais amplitude que se pretenda atribuir ao conceito, permanece ele limitado à escuta e eventual gravação da conversa telefônica, quando praticada por terceira pessoa, diversa dos interlocutores. Somente a "terzietà", referida pela doutrina italiana, écapaz de caracterizar a interceptação.

Rangel (2000) restringe ainda mais este conceito, afirmando que somente se caracteriza a interceptação quando a captação é feita por terceira pessoa sem o conhecimento dos interlocutores.

De qualquer forma, o que interessa para o presente artigo é que a interceptação das comunicações telefônicas cuida da captação de sons e palavras mantidas por possíveis autores de crimes por uma terceira pessoa, no caso, os investigadores.

No curso da realização da interceptação, os investigadores desenvolvem e executam diversas ações para que o resultado da medida seja mais um elemento esclarecedor da verdade, finalidade última da investigação criminal. 
Por tal motivo, embora escutem e gravem as conversas captadas sem causar interferências, sob pena de inviabilizar a medida, os diálogos interceptados devem ser interpretados e analisados, à medida que aconteçam, para que indiquem o melhor caminho a ser percorrido na apuração dos fatos e das condutas supostamente delituosas.

Os investigadores não são meros espectadores que registram as conversas interceptadas. A atividade exige acompanhamento constante para que ela se adapte ao comportamento dos investigados e para que seja complementada com outras diligências indispensáveis. Em ambos os casos, o sucesso da investigação dependerá da capacidade de análise dos investigadores a respeito das conversas captadas.

E para que os diálogos sejam analisados de forma coerente e verdadeira, o estudo da linguagem certamente fornecerá instrumentos valiosos para a correta compreensão dos acontecimentos. Nos dizeres de Dutra (2001, p.13): "não há investigação sobre o mundo que não se faça mediante instrumentos linguísticos e por meio de práticas e procedimentos socialmente estabelecidos".

\section{As Dimensónes da Linguagem}

O investigador que ouve os diálogos interceptados analisa as três dimensões da linguagem presentes na conversação: pragmática, sintática e semântica. E, a partir dessa análise, formula suas hipóteses, dirige suas ações e conclui seus resultados.

Os estudos sobre a filosofia da linguagem, hoje amplamente utilizados pela epistemologia e pela filosofia da ciência, abordam cada uma destas dimensões (DUTRA, 2008) e podem ser aplicados para explicar como devem ser analisadas as conversas captadas pela interceptação das comunicações telefônicas.

De forma resumida, podemos compreender a dimensão semântica da linguagem como sendo a relação entre as palavras e os objetos a que se referem (significado). Já a dimensão sintática é a relação das palavras entre si, dentro de uma organização pré-estabelecida (regra). Por fim, a dimensão pragmática relaciona o uso das palavras com o falante, o ouvinte e os demais elementos que contextualizam a comunicação (uso). 
Evidentemente que todas as dimensões da linguagem estão inter-relacionadas e o completo entendimento do processo comunicativo depende do conhecimento sobre as três dimensões acima apontadas. Portanto, não é apropriado, por exemplo, que um investigador analise um diálogo captado em língua estrangeira se ele não domina o referido idioma, embora possa compreender boa parte do significado de algumas palavras utilizadas. Da mesma forma, não será relevante a interpretação que desconsidera por completo o modo como são usadas determinadas palavras, pretendendo impor aos termos captados sentidos que o falante não lhes atribuiu.

Por exemplo, se interceptássemos: "O ovo é verde. Mas posso fazer o pato latir." A princípio, não se poderia concluir muita coisa sobre o sentido deste proferimento, caso se considerasse, tão somente, o significado semântico das palavras, pois a cor dos ovos não é verde, e também porque os patos não podem latir. Embora a sintática colabore para a compreensão mínima desta sentença, uma vez que as palavras foram corretamente empregadas segundo as funções que exercem dentro das regras da linguagem corrente, a pragmática possibilitaria uma redução nas possibilidades interpretativas, quando se compreende em quais contextos e para quais objetos o falante utiliza tais expressões. Nos tópicos seguintes, a dimensão pragmática da linguagem será tratada de forma mais detalhada.

\section{3.i A Dimensão PRAGMÁtica}

As lições de Ludwig Wittgenstein presentes nas suas Investigações Filosóficas (1999) esclarecem por meio da ideia do "jogo de linguagem" como os signos, as palavras e expressões podem ter significados diferentes de acordo com o uso dado a eles (pragmática), conforme expóe Danilo Marcondes (2006, p. 221):

Segundo Wittgenstein, o significado não deve ser entendido como algo de fixo e determinado, como uma propriedade inerente à palavra, mas sim como a função que as expressöes linguisticas exercem em um contexto especifico e com objetivos específicos. O significado pode, por conseguinte, variar dependendo do contexto em que a palavra é utilizada e do propósito deste uso.

Neste primeiro momento, esta concepção pragmática relaciona as expressões utilizadas aos contextos em que elas se inserem, de modo a dotar de sentido os proferimentos realizados. Assim, o mesmo termo poderá ser 
usado para designar situações e pessoas totalmente distintas, seja se valendo do seu significado semântico mais comum e abrangente, ou significando coisas e objetos de modos inicialmente inimagináveis.

Cite-se, por exemplo, o uso da palavra "alemão". Se inicialmente se referia apenas àquela pessoa originária da Alemanha (significado semântico), hoje pode representar também, para alguns grupos, qualquer pessoa de origem estrangeira, ou até mesmo designar um inimigo, um intruso, e para outras comunidades, a polícia. Semanticamente é impossível explicar a relação entre "alemão" e "polícia", mas é bem provável que crianças em favelas cariocas (portanto contextualizadas) possam fazer tal conexão sem maiores dificuldades quando utilizam este termo na sua linguagem cotidiana.

Os diálogos interceptados pela medida investigativa deverão ser cuidadosamente interpretados conforme o contexto em que foram proferidos, devendo ser observadas todas as circunstâncias que envolvem o falante, o ouvinte, o assunto discutido, as gírias e o regionalismo linguístico.

Considerando os aspectos que envolvem o crime, a investigação criminal e a própria interceptação das comunicações, a abordagem pragmática da linguagem fornece respostas mais adequadas para explicar estes fenômenos, quando empiricamente considerados.

O crime é, por definição, sinônimo de conduta ilegal, ilícita e reprovável. Evidentemente que seus autores, via de regra, utilizam-se de artifícios que procuram escondê-lo ou disfarçá-lo, de modo a impedir a ação repressora do Estado. Estes artifícios também se refletem na linguagem travada por eles, com a utilização de gírias, senhas, códigos, metáforas e codinomes, na tentativa de se manterem inteligíveis tão somente para os integrantes do grupo envolvido na prática das infrações.

Assim, quando interceptados os diálogos mantidos entre os possíveis autores destes crimes, far-se-á perceber o uso desta linguagem cifrada, cujo sentido não é facilmente compreendido. Embora em algumas situações as conversas interceptadas possam ser analisadas conforme os significados semânticos das expressões captadas, não há dúvidas de que, na imensa maioria das investigações, é o uso da linguagem que determina o sentido dos diálogos relevantes, e consequentemente estabelece a forma como devem ser interpretadas as conversas interceptadas. 
A fim de exemplificar os parágrafos anteriores, é praticamente impossível interceptar diálogo mantido entre traficantes de drogas nos quais sejam usadas, literalmente, as palavras "drogas", "cloridrato de cocaína”, "cocaína”, "tetrahidrocanabinol”, "maconha”, "quilos", "transporte", "estoque”, "depósito", etc. Na maior parte dos casos são utilizadas figuras de linguagem para simbolizar tanto o produto que comercializam como a forma utilizada para realizar suas transaçôes. Eles podem ser chamados por qualquer outro termo, de variadas formas, cujo sentido é conhecido somente pelos possíveis criminosos.

Sob a perspectiva da investigação criminal, as conclusões obtidas por meio da análise feita sobre o uso das expressões podem esclarecer melhor os fatos em apuração, em contraposição àquelas que se baseiam, primordialmente, na interpretação semântica dos diálogos.

Evidentemente que será muito mais trabalhoso e por vezes infrutífero, em razão dos limites temporais e legais da medida, concluir estudos com base, unicamente, no uso de palavras proferidas em escassas oportunidades.

Contudo, é certo que ao investigador não deve interessar qual o significado semântico, por exemplo, das palavras: "flor", "viagem", "cerveja", "tênis", "bilhetes", "plantas", "bola", "drogas", "dinheiro", "esquema”, etc., quando eventualmente captadas no bojo dos diálogos. No caso deve se ater, primordialmente, ao uso dado a estas palavras pelas pessoas investigadas, no contexto da investigação. Ocasionalmente, o sentido dado pelo uso pode ser equivalente ao significado semântico, e por outras vezes, o investigador deverá presumir que o sentido semântico seja, de fato, o pretendido pelos interlocutores, quando não houver motivo que indique outra possibilidade.

Porém, Marcondes (2006) afirma que Carnap problematizou a construção de uma concepção pragmática, como proposta por Wittgenstein, pois em que pese corroborar tal pensamento no que tange à diversidade de sentidos proporcionada pelo uso da linguagem, entende que seria impossível criar uma sistematização teórica sobre ele (o uso), uma vez que estaria sujeito a situações extremamente complexas e variadas (como exemplificado acima) que impediriam a abstração e generalização de um estudo filosófico ou científico. Neste sentido, somente quando a linguagem atinge níveis maiores de abstração, como se percebe na sintática e na semântica, seria possível estruturar concepções teóricas sobre ela. 
De qualquer forma, todas as dimensões da linguagem possuem certo grau de abstração, embora a semântica acumule maior grau, pois "distante das situações ordinárias de fala e comunicação" (DUTRA, 2008, p. 55). Não obstante, o uso também deve ser considerado uma abstração, seja ele mais restrito, relativo a uma classe de proferimentos, seja de modo mais amplo, referente a "uma classe de relações entre proferimentos e contextos" (Op. cit., p. 59).

\section{Teoria dos Atos de Fala}

Uma das tentativas de sistematizar uma análise pragmática da linguagem foi proposta por John Langshaw Austin (1990), resultante na Teoria dos Atos de Fala - TAF. Em síntese apertada, dentro da teoria mencionada, a unidade básica de significação da linguagem é o "ato de fala", que se desdobra em "três dimensões integradas ou articuladas", quais sejam: "os atos locucionário, ilocucionário e perlocucionário” (MARCONDES, 2006, p. 224).

Visando esclarecer os conceitos trazidos por Austin, nos dizeres de Ottoni (2002):

Para Austin o ato de fala é composto de três partes, três atos simultâneos: um ato locucionário, que produz tanto os sons pertencentes a um vocabulário quanto a articulação entre a sintaxe e a semântica, lugar em que se dá a significação no sentido tradicional; um ato ilocucionário, que é o ato de realização de uma ação através de um enunciado, por exemplo, o ato de promessa, que pode ser realizado por um enunciado que se inicie por eu prometo..., ou por outra realização; por último, um ato perlocucionário, que é o ato que produz efeito sobre o interlocutor.

Conforme Austin (1990), o ato de falar não se resume na transmissão de uma mensagem. Assim, quando alguém fala, além de comunicar algo (ato locucionário), ele realiza uma ação (ato ilocucionário) e gera efeitos no ouvinte (ato perlocucionário).

Se captarmos o seguinte proferimento: "ofereço-te um prêmio", poderemos perceber a mensagem transmitida, relativa aos dizeres do enunciado "ofereço-te um prêmio", mas também a realização do ato de oferecer, por intermédio de um verbo perfomativo (ofereço), de onde decorre a força ilocucionária da sentença. A força ilocucionária deste ato de fala poderia ser realizada de outras variadas maneiras, por proferimentos 
diversos, conforme as circunstâncias do contexto, como por exemplo: "dar-te-ei uma gratificação" ou "prometo te pagar uma quantia". Em todas estas frases o falante se compromete a fazer algo, no caso, entregar dinheiro ou bens. De modo geral, o ouvinte deve apresentar reaçóes (ato perlocucionário) quando recebe a mensagem, seja aceitando, recusando, indignando-se, satisfazendo-se, etc.

Para Austin (1990), dizer é fazer! Não há como negar que os diálogos interceptados poderão fazer a prova material de crime, como por exemplo, naqueles em que o interceptado oferece o pagamento de vantagem indevida a funcionário em razão da função. Por exemplo, o crime de corrupção ativa estará devidamente consumado e provado, se além da mensagem contida nas palavras emitidas, ficar demonstrado que por meio de seus dizeres, o interlocutor prometeu (ato de prometer) tal vantagem.

Austin (1990) apresenta uma classificação provisória contendo as cinco categorias básicas de atos ilocucionários: vereditivos, expositivos, exercitivos, comportativos e compromissivos. No exemplo acima citado, a força ilocucionária presente nos proferimentos indicam que eles devem ser incluídos entre os atos ilocucionários compromissivos, pois o falante se compromete a fazer algo. Embora John Searle (2002) não faça objeção à classificação dos atos ilocucionários compromissivos, na forma proposta por Austin, ele cria uma nova taxionomia, em que poderão ser assim classificados: assertivos, diretivos, expressivos, declarativos, além dos já mencionados compromissivos.

Para criar a sua taxionomia dos atos de fala, Searle (2002, p. 3) se vale de doze "dimensões significativas" como critérios de classificação, frisando, contudo que uma delas, qual seja: o propósito do ato, chamado por ele de "propósito ilocucionário", seja a mais importante (SEARLE, 2002, p. 4).

Searle (2002) fornece alguns exemplos para tentar esclarecer o que pretende que com o termo "propósito ilocucionário": Exemplo n..$^{\circ} 1$ - o propósito de uma descrição é ser uma representação; Exemplo n. ${ }^{\circ} 2$ - o propósito de uma promessa é obrigar o falante a fazer algo; Exemplo n. 3 - o propósito dos pedidos e dos comandos é a tentativa de levar o ouvinte a fazer algo. Com o último exemplo (3), ele pretende dizer que o propósito ilocucionário é o mesmo entre pedidos e comandos, mas os atos possuem forças ilocucionárias distintas em razão de outros elementos que a integram. 
Assim, Searle (2002, p. 46) conclui, após sistematizar sua classificação dos atos de fala, e por conseguinte, analisar as formas como a linguagem pode ser utilizada:

Se adotamos o propósito ilocucionário como a noção básica para a classificação dos usos da linguagem, há então um número bem limitado de coisas básicas que fazemos com a linguagem: dizemos às pessoas como as coisas são, tentamos levá-las a fazer coisas, comprometendo-nos a fazer coisas, expressamos nossos sentimentos e atitudes, e produzimos mudanças por meio de nossas emissões.

Da mesma forma, por mais incompreensível que sejam alguns dos termos utilizados nos diálogos captados, tais como gírias, códigos ou senhas, seria possível, em muitos proferimentos, inferir a força ilocucionária dos atos de fala, por intermédio do propósito ilocucionário e a partir daí, como um instrumento de análise, reduzir as possibilidades interpretativas destes mesmos diálogos.

Ciente das possibilidades ilocucionárias de um ato de fala, em conjunto com os demais elementos do contexto e com a frequência de utilização destes termos, poderá o investigador interpretar e concluir com o maior grau de acerto o significado das mensagens interceptadas.

Em síntese, elucidar ou reduzir as ações contidas nos atos de fala é apontar quais os significados atribuídos pelos falantes às palavras usadas nos diálogos. E estas ações, via de regra, são o reflexo da vontade do falante, elemento de suma importância para o direito penal.

\section{I ATOS DE FALA INDIRETOS}

Com base na teoria proposta por Austin, Searle (2002) acrescenta que em diversos casos a significação dos proferimentos não se revela de maneira simples, isto é, como correspondência exata e única entre a literalidade dos termos e o sentido da sentença. Assim, propõe a existência de atos que possuam mais de uma força ilocucionária, chamando-os de atos de fala indiretos, quando "um ato ilocucionário é realizado indiretamente através da realização de um outro." (Op. cit., p. 49).

A fim de ilustrar o ato de fala indireto, Searle (2002) nos dá o seguinte exemplo: "Você pode alcançar o sal?" Neste exemplo, a força ilocucionária não se resume à pergunta explicitada, mas também evoca um pedido implícito para que o ouvinte passe o sal, caso isso lhe seja possível (condição preparatória). 
Em resumo, Searle (2002, p. 50) diz que "em atos de fala indiretos, o falante comunica ao ouvinte mais do que realmente diz".

E para que a significação indiretamente contida neles possa ser compreendida é necessário, teoricamente, o seguinte aparato:

[...] uma teoria dos atos de fala, alguns principios gerais de conversação cooperativa (alguns dos quais foram discutidos por Grice (1975) e a informação fatual prévia compartilhada pelo falante e pelo ouvinte, além da habilidade do ouvinte para fazer inferências. (SEARLE, 2002, p. 50).

$\mathrm{Na}$ teoria formulada por Grice (1989), referente às implicaturas conversacionais, os diálogos são produzidos por esforços cooperativos dos falantes, em que eles reconhecem um propósito e um direcionamento comum para o encaminhamento dos assuntos. Assim, os participantes de um diálogo, ao contribuírem no desenvolvimento da conversa, seguem, via de regra, um "princípio de cooperação".

Assim, quando se intercepta possível autor de crime, presume-se que o falante e o ouvinte interceptados, ao conversarem pelo telefone, possuam interesses comuns, mesmo que sejam aqueles mínimos que possibilitem uma conversa inteligível.

Nas interceptações das comunicações telefônicas, a imensa maioria dos diálogos captados, que possuem relevância para investigação criminal, caracteriza-se como atos de fala indiretos.

Cite-se, por exemplo:

Falante X: "Preciso falar com você."

Falante Y: "Estou indo agora para aí."

Falante X: "Quinze horas, onde W está."

Falante Y: "Certo. Tchau."

Evidentemente que $\mathrm{X}$ não pretende, tão somente, falar com Y, mesmo porque eles já estão se falando através do telefone. Com toda a certeza, $\mathrm{X}$, além da necessidade de falar (significação literal - ato ilocucionário secundário declarativo), convida Y para um encontro (ato ilocucionário primário diretivo). Utiliza-se, portanto, a teoria dos atos de fala. 
Na sequência, demonstrando que inferiu a mensagem, Y se compromete a ir ao encontro de $\mathrm{X}$ (ato ilocucionário secundário - compromissivo), mas também propõe, ao mesmo tempo, o momento e o local do encontro (ato ilocucionário primário - diretivo).

Em seguida, $\mathrm{X}$ recusa, por meio de uma declaração, as indicações de hora e local para o encontro proposto no ato de fala indireto de Y, e sugere, no mesmo ato de fala, o momento (trinta minutos depois) e o local (onde W está).

Por fim, Y compreende, por compartilhar com X, informações fatuais prévias referentes ao momento e ao local do encontro (onde W está) e ao mesmo tempo se compromete com o encontro.

Para uma investigação criminal bem sucedida, na ocasião em que seja interceptado o mencionado diálogo, a equipe policial deve ter a capacidade de entender as forças ilocucionárias existentes nas expressões captadas, mas também deve dispor da mesma capacidade de inferência e também da informação fatual prévia dos interceptados, tal como o horário em que se comunicam e o local onde irão se encontrar, especialmente para que possam registrar o possível encontro, de forma a contextualizar as comunicações interceptadas.

\section{Conclusões}

A interceptação das comunicações telefônicas é uma das mais eficazes e eficientes técnicas de investigação criminal, pois possibilita um conhecimento profundo sobre o fato investigado, seus autores e partícipes.

Objeto de inúmeros estudos sobre os limites constitucionais e legais de sua aplicação, pouco se escreveu a respeito da forma como é analisado o seu conteúdo. E considerando que a medida consiste na interceptação de palavras e sons transmitidos, tratar de seu conteúdo é se valer dos estudos sobre a linguagem.

A linguagem pode ser analisada por meio de três dimensões inter-relacionadas, quais sejam: sintática, semântica ou pragmática. De fato, todas contribuem para proporcionar a compreensão do fenômeno comunicativo.

Contudo, quando se trata dos aspectos relacionados ao crime è̀ forma de investigá-lo, a dimensão pragmática assume maior importância. No caso, os diálogos interceptados estarão repletos de metáforas, gírias, 
códigos, senhas, codinomes e os sentidos atribuídos pelos interlocutores aos termos captados, como proposto por Wittgenstein, é que vão gerar significados relevantes para a investigação criminal. É preciso descobrir o sentido dado pelos interlocutores para as palavras captadas para que se possam atingir resultados satisfatórios.

Embora existam dificuldades para o enfrentamento teórico de uma abordagem pragmática da linguagem, em razão de sua abstração mínima, Austin propôs uma Teoria dos Atos de Fala na qual procura transpor tais obstáculos.

No caso, Austin (1990) identifica três dimensões da unidade básica da linguagem (o ato de fala): o ato locucionário, o ilocucionário e o perlocucionário. Ou seja, a mensagem (ato locucionário) somente poderá ser compreendida pragmaticamente quando entendida a ação contida neste proferimento (ato ilocucionário) juntamente com os seus efeitos no interlocutor (ato perlocucionário). Do ponto de vista jurídico-criminal, não há dúvidas de que um ato de fala pode caracterizar uma ação delituosa e gerar reações igualmente criminosas. De fato, como propôs Austin, dizer é fazer.

Aprofundando nos estudos sobre os atos de fala, Searle identifica um dos principais aspectos do ato ilocucionário: o propósito ilocucionário, quando discorre sobre a classificação desses. Conhecendo o propósito ou a finalidade da força ilocucionária do ato, diz Searle (2002), reduzimos muito as possibilidades de interpretação de um ato de fala. Neste aspecto, no bojo de uma investigação criminal, ao captar um diálogo, e identificar o propósito daqueles proferimentos diminuem-se muito as possibilidades interpretativas, muitas vezes confundidas por termos cujos sentidos são inicialmente desconhecidos dos investigadores.

Searle também propõe a existência de atos de fala indiretos. Esses possuem mais de uma força ilocucionária e significados mais extensos do que os atos de fala diretos. Para sua adequada compreensão, o aparato teórico necessário depende de uma teoria de atos de fala, princípios conversacionais cooperativos, uma capacidade inferencial e um conhecimento fatual prévio. 
Na maioria dos diálogos interceptados, é possível aplicar as teorias pragmáticas da linguagem para reduzir as possibilidades de interpretação e proporcionar o acompanhamento adequado do fato investigado. Compete ao investigador entender os dizeres captados sob a perspectiva do investigado, especialmente interpretar os termos interceptados com os significados propostos pelos interlocutores para que a medida atinja resultados satisfatórios e suas conclusões sejam fidedignas.

Daniel Fabio Fantini

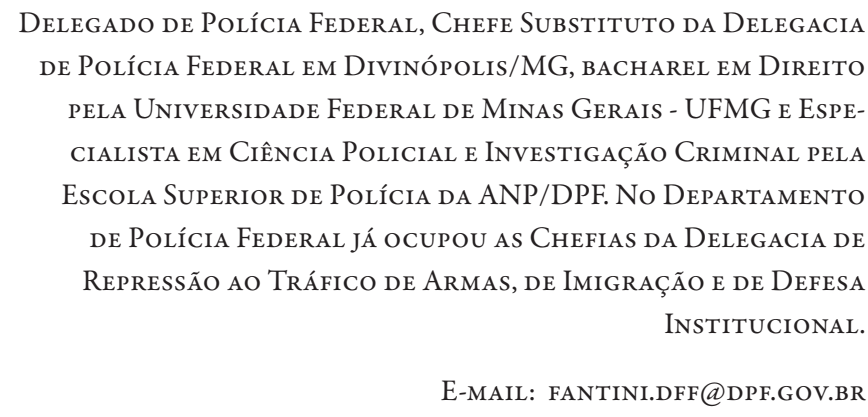

Abstract

\section{Phone-tapping and Language}

This paper presents the linguistic aspects inherent to the content of intercepted telephone exchanges. From this viewpoint, and in the light of linguistic studies, the subject has been broached from a pragmatic dimension while considering its empirical application. With regard to the difficulties in systematizing a theoretical approach to the use of language, the speech act and indirect speech act theories, respectively set forth by Austin and Searle, offer adequate solutions to explain the linguistic phenomena relating to conversations between possible perpetrators of crime, intercepted during criminal investigation. The theories mentioned provide theoretical tools for investigators whereby they are able to appropriately interpret the meanings of words recorded in a telephone tap according to their utilization. Namely, by emphasizing that utterance is equivalent to action, they reveal that the language recorded may be better understood when one analyzes the illocutionary forces driving communicative speech acts. Lastly, the speech act theory furnishes elements that enable investigators to make sense of speech acts with more than one illocutionary force, one explicit and the other implicit, facilitating understanding of the tapped conversations, even if they consist of the coded expressions, slang, or encrypted utterances frequently utilized amongst perpetrators.

KEYWORDS: Telephone tapping. Criminal investigation. Language. Pragmatics. Language games. Wittgenstein. Speech acts. Austin. Searle. 


\section{REFERÊNCIAS}

AUSTIN, John Langshaw. Quando dizer é fazer. Tradução de Danilo Marcondes de Souza Filho. Porto Alegre: Artes Médicas, 1990.

DUTRA, Luiz Henrique de Araújo. Pragmática da Investigação Científica. São Paulo: Edições Loyola, 2008.

DUTRA, Luiz Henrique de Araújo. Verdade e Investigação. São Paulo: E.P.U., 2001.

GRICE, H. P. Lógica e Conversação. Tradução de João Wanderley Geraldi. In: DASCAL, Marcelo. (org.) Problemas, críticas, perspectivas da linguística. Campinas, Unicamp. 1982.

GRINOVER, Ada Pellegrini. O regime brasileiro das interceptações telefônicas. Revista CEJ, Brasília, v. 1, n. 3 set./dez. 1997. Disponível em: <http://www2.cjf.jus.br/ojs2/index.php/cej/article/ viewArticle/108/151>. Acesso em: 19 Abr 2011.

MARCONDES, Danilo Marcondes de Souza Filho. A Teoria dos Atos de Fala como concepção pragmática de linguagem. FILOSOFIA UNISINOS v. 7, n. 3, set/2006. Disponível em: <http://www. unisinos.br/publicacoes_cientificas/images/stories/pdfs_filosofia/ vol7n3/art01_marcondes.pdf>. Acesso em 14. Jun 2011.

OTTONI, Paulo. John Langshaw Austin e a Visão Performativa da Linguagem. DELTA, São Paulo, v. 18, n. 1, 2002. Disponível em: $<$ http://www.scielo.br/scielo.php?script=sci_arttext\&pid=S010244502002000100005\&lng=en\&nrm=iso >. Acesso em: 01 Jun 2011.

RANGEL, Paulo. Breves considerações sobre a Lei 9296/96 (interceptação telefônica). Jus Navigandi, Teresina, ano 5, n. 41, 1 maio 2000. Disponível em: <http://jus.uol.com.br/revista/texto/195>. Acesso em: 19 abr. 2011.

SEARLE, John R. Expressão e significado: estudos da teoria dos atos da fala. Tradução de Ana Cecília G. A. de Camargo, Ana Luiza Marcondes Garcia. 2. ed. São Paulo: Martins Fontes, 2002.

WITTGENSTEIN, Ludwig. Investigações filosóficas. Tradução de Jose Carlos Bruni. São Paulo: Editora Nova Cultural, 1999 (Coleção Os Pensadores: Wittgenstein).

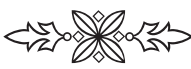

